\title{
Relationship Between Plant Vascular Architecture and Within-Plant Distribution of 'Candidatus Liberibacter solanacearum' in Potato
}

\author{
W. Rodney Cooper • Piedad E. Alcala • Nina M. Barcenas
}

Published online: 11 October 2014

(C) The Author(s) 2014. This article is published with open access at Springerlink.com

\begin{abstract}
Candidatus Liberibacter solanacearum' is an important pathogen of Solanaceous crops that causes zebra chip disease of potato. This pathogen is transmitted among plants by the potato psyllid Bactericera cockerelli. Within-plant spatial variability in Liberibacter infection impedes the ability to detect the bacterium before the onset of visible symptoms. The goal of our study was to test whether vascular architecture of potato explains the uneven distribution of Liberibacter after inoculation of leaves. The movement of rhodamine B among leaves was used to identify vascular connectivity among leaves. Three weeks after inoculating a single leaf with Liberibacter, the pathogen infected significantly more leaflets that had direct vascular connectivity with the inoculated leaf than leaflets with minimal connectivity. In a separate study, significantly more psyllids confined to whole leaves with direct vascular connectivity to a Liberibacter-infected leaf acquired the pathogen than did psyllids confined to leaves with indirect or partial connectivity to the infected leaf. Using fluorescence in situ hybridization, the pathogen was observed in the inner and outer phloem above and below the export leaf, respectively, corresponding with passive movement of Liberibacter in the phloem. Results of this study indicate that the distribution of Liberibacter in potato is at least partly limited by vascular architecture. This knowledge should improve the design of sampling methods to detect Liberibacter in asymptomatic plants.
\end{abstract}

W. R. Cooper $(\bowtie)$

USDA/Agricultural Research Service, Yakima Agricultural Research

Laboratory, Wapato, WA 98951, USA

e-mail: Rodney.Cooper@ars.usda.gov

P. E. Alcala $\cdot$ N. M. Barcenas

Department of Natural Sciences, Heritage University, Toppenish, WA 98948, USA
Resumen 'Candidatus Liberibacter solanacearum' es un patógeno importante en cultivos de solanáceas que causa la enfermedad de "zebra chip" de la papa. Este patógeno se transmite entre las plantas por el psílido de la papa Bactericera cockerelli. La variabilidad espacial dentro de la planta en la infección por Liberibacter impide la habilidad para detectar la bacteria antes del establecimiento de síntomas visibles. La meta de nuestro estudio fue probar si la arquitectura vascular de la papa explica la distribución desuniforme de Liberibacter después de la inoculación de las hojas. Se usó el movimiento de rodamina B entre hojas para identificar la conectividad vascular entre hojas. Tres semanas después de haber inoculado una hoja con Liberibacter, el patógeno infectó significativamente más folíolos que tuvieron conectividad vascular directa con la hoja inoculada, que folíolos con conectividad mínima. En un estudio aparte, significativamente más psílidos confinados a hojas completas con conectividad vascular directa a una hoja infectada con Liberibacter adquirieron el patógeno, que los confinados a hojas con conectividad indirecta o parcial con la hoja infectada. Mediante el uso de hibridación de inflorescencia in situ, se observó al patógeno en el floema interno y externo, arriba y debajo de la hoja exportadora, respectivamente, lo que correspondió con movimiento pasivo de Liberibacter en el floema. Los resultados de este estudio indican que la distribución de Liberibacter en papa es por lo menos parcialmente limitada por la arquitectura vascular. Este conocimiento podría mejorar el diseño de métodos de muestreo para detectar Liberibacter en plantas asintomáticas.

Keywords Liberibacter psyllaurous · Orthostichous · Bactericera cockerelli · Solanum 


\section{Introduction}

'Candidatus Liberibacter solanacearum' is a pathogen of Solanaceous crops that causes zebra chip disease of potato (Solanum tuberosum L.) (Munyaneza 2012). Zebra chip disease is characterized by plant decline and eventual death, substantial yield reductions, and striped patterns in tubers that render them unmarketable. Liberibacter is transmitted among plants by the potato psyllid, Bactericera cockerelli (Šulc) (Hemiptera: Triozidae), which acquires the pathogen by feeding on infected phloem. Current research efforts seek to better understand the interactions among Liberibacter, the potato psyllid, and host plants. These interactions include variations among potato varieties in their resistance or tolerance to the disease, variations among psyllid populations and life-stages in their ability to acquire and transmit Liberibacter, and how geographic distributions influence overwintering of Liberibacter and psyllids (Munyaneza 2012, Cooper et al. 2013, Swisher et al. 2013a, 2013b). An important application of understanding these interactions is the ability to accurately diagnose Liberibacter infection in plants in the absence of visual symptoms.

Liberibacter is phloem-limited, and within-plant distribution of Liberibacter is highly variable (Levy et al. 2011). This variability impedes the ability to accurately diagnose Liberibacter infection using PCR because leaves are not infected uniformly. One possible explanation for within-plant variability in Liberibacter distribution is limitations imposed by vascular architecture or connectivity among leaves. Vascular connectivity among leaves is based on their phyllotactive arrangement. In general, leaves that are vertically aligned in their phyllotactive arrangement share direct vascular connections and transport the greatest amounts of vascular contents, leaves with adjacent alignment share partial vascular connections and transport less, and leaves with an opposite alignment lack vascular connections and transport the least (Dimond 1966; Orians et al. 2000; Orians 2005). Vascular architecture can also refer to the arrangement of vascular bundles in plant stems. The vascular arrangement in stems of Solanaceous plants differs from most other plant Families by having a bicollateral vascular system (McCauley and Evert 1988). The bicollateral vascular system contains two types of phloem in the stem. The inner phloem is located internal to the xylem and transports vascular products upward whereas the outer phloem is located external to the xylem and transports vascular products downward toward the roots.

The influence of vascular architecture on distribution of Liberibacter has not been studied previously. Although results of previous studies indicated that the movement of phloemlimited viruses is restricted by vascular connectivity among leaves (Leisner et al. 1992; Andrianifahanana et al. 1997; Gosalvez-Bernal et al. 2008), the movement of phytoplasmas, which are phloem-limited bacteria, does not appear to be limited by vascular architecture (Kuske and Kirkpatrick 1992; Constable et al. 2003; Christensen et al. 2004). Instead, phytoplasmas tend to accumulate in source leaves, perhaps because they attach to the sieve-element membrane, are retained in the sieve pores, or are self-mobile (Christensen et al. 2004). Genes involved in cell-adhesion and self-mobility have been identified from ' $\mathrm{Ca}$. Liberibacter solanacearum,' so within-plant distribution of this pathogen in potato may follow similar patterns observed for phytoplasmas (Lin et al. 2011).

The overall goal of this study was to investigate whether the distribution of ' $\mathrm{Ca}$. Liberibacter solanacearum' in potato is influenced by plant vascular architecture. Specific objectives were to 1) map the vascular connectivity among leaves of potato using a tracer dye, 2) determine whether distribution of ' $\mathrm{Ca}$. Liberibacter solanacearum' is limited by vascular connectivity among leaves of potato, and 3 ) determine the distribution pattern of Liberibacter in the stems of potato.

\section{Materials and Methods}

Plants and Insects B. cockerelli infected or uninfected with Liberibacter were obtained from separate laboratory colonies that originated from insects collected from fields of potato near Prosser, WA in 2012. Both colonies were maintained on potato 'Ranger Russet' and tomato 'Moneymaker' in environmental control rooms maintained at $25^{\circ} \mathrm{C}$ with a $16: 8$ (L:D) $\mathrm{h}$ photoperiod and $50 \%$ relative humidity. Adult psyllids from both colonies were periodically tested for the presence or absence of Liberibacter using diagnostic PCR as described below.

'Ranger Russet' potatoes were grown in a greenhouse from certified virus-free tubers in $900-\mathrm{cm}^{3}$ plastic pots with $1: 2: 2$ ratio of pumice, sand, and peat. Plants were fertilized at planting with slow release Osmocote (Scotts Miracle-Gro Company, Marysville, $\mathrm{OH}$ ), and once every 2 weeks with Miracle-Gro (Scotts Miracle-Gro Company). Supplemental lighting provided a 16:8 (L:D) h photoperiod.

Plants with seven fully expanded leaves were used for experiments. The second fully-expanded leaf from the soil was used as an export or inoculation leaf and was designated as leaf 0 . The location of other leaves were designated in reference to the export or inoculation leaf, the leaf below leaf 0 was designated as leaf -1 , and the leaves above the export leaf were designated as leaves 1 through 5 .

Migration of Rhodamine B Vascular connections among leaves were assessed by observing the migration of a rhodamine B from an export leaf to other leaves and leaflets of potato plants following the method described by Orians et al. (2000). The terminal leaflet of the second fully expanded leaf (leaf 0 ) of each plant was excised, and the cut petiole attached 
to the plant was inserted into a $1.5-\mathrm{ml}$ microfuge tube filled with a solution of $0.25 \%$ rhodamine B in $25 \mathrm{mM}$ EDTA. A 2 to $3-\mathrm{mm}$ diameter hole in the lid of the microfuge tube provided entry for the cut petiole. The plants were placed in a growth chamber (model I30BLL, Percival Scientific Inc., Perry IA) maintained at $25^{\circ} \mathrm{C}$ with the lights on. After $4 \mathrm{~h}$, the presence or absence of dye was observed in the three terminal leaflets of leaves $-1,1,2,3,4$, and 5 . After observations of foliar accumulation of rhodamine $\mathrm{B}$, two $\approx 0.5-\mathrm{mm}$ thick sections were cut perpendicular to the plant stem at midpoints between nodes above and below the source leaf. The presence or absence of rhodamine B in the stem phloem was observed under 200× (Zeis Axiolab, Carl Zeiss USA, Thornwood, NY). Samples were photographed using a DP25 camera mounted to the microscope and operated using the CellSens software (Olympus America Inc., Central Valley, PA). The experiment was repeated 4 times (trials). The first trial included 10 plants and the remaining three trials each included 8 plants.

Migration of Liberibacter Five Liberibacter-infected or noninfected adult psyllids were confined to the terminal leaflet of the second fully expanded leaf of potato plants for $48 \mathrm{~h}$ using a sleeve cage. Insects were tested for Liberibacter infection using PCR after they were removed from the plants. The plants were maintained for 3 weeks in $25^{\circ} \mathrm{C}$ to allow Liberibacter to multiply and spread throughout the plant (Sengoda et al. 2013). After 3 weeks, the three terminal leaflets of leaves -1 through 5 (relative to the inoculation leaf designated as leaf 0 ) were collected from each plant and tested for Liberibacter using PCR. The experiment was conducted twice (trials), and each trial included 10 plants exposed to Liberibacter-infected psyllids and 2 plants exposed to noninfected psyllids.

In separate assays, three Liberibacter-infected psyllids were confined to the whole of leaf 0 , and three non-infected psyllids were confined to each leaf at positions 1 through 5. The insects were collected after 1 week, and each group of three insects was tested for Liberibacter infection using PCR. The experiment was conducted 4 times (trials), and each trial included 3 plants.

In both experiments (Liberibacter infection in leaves after 3 weeks and in insects after 1 week), stem slices were collected from plants as described for experiments examining the movement of rhodamine $\mathrm{B}$, and the presence or absence of Liberibacter in the plant stems was assessed using fluorescence in situ hybridization.

DNA Extraction and PCR DNA was extracted from plants and psyllids using the cetyltrimethlyammonium bromide method (Zhang et al. 1998). Leaf samples were placed in Universal Extraction Bags (Eurofins STA Laboratories Inc, Longmont, $\mathrm{CO})$ with $500 \mu \mathrm{l}$ of CTAB buffer $(2 \%$ cetyltrimethlyammonium bromide, $1.4 \mathrm{M} \mathrm{NaCl}, 20 \mathrm{mM}$
EDTA, $100 \mathrm{mM}$ Tris-HCl pH 8.0, and $0.2 \%$ mercaptoethanol). After pulverizing the leaf with a pestle, $300 \mu \mathrm{l}$ of buffer containing the leaf homogenate was transferred to a microfuge tube and $8 \mu$ of $5 \%$ lysozyme was added. For DNA extraction from psyllids, the insects were ground in $500 \mu \mathrm{l}$ of CTAB buffer using a micropestle in a $1.5 \mathrm{ml}$ microfuge tube. Plant and insect samples were incubated in $65^{\circ} \mathrm{C}$ for $30 \mathrm{~min}$, and then maintained at room temperature for $3 \mathrm{~min}$ before adding $500 \mu \mathrm{l}$ of ice-cold chloroform. After centrifugation at $16,000 \times \mathrm{g}$ for $10 \mathrm{~min}$, the aqueous layer was transferred to 0.6 volume of $100 \%$ isopropanol with $1 \mu \mathrm{l}$ of glycogen $(5 \mathrm{mg} / \mathrm{ml}$; Ambion, Austin, TX). Samples were held on ice for $20 \mathrm{~min}$ to precipitate DNA. After centrifugation, the resulting pellet was washed with ice-cold $70 \%$ ethanol, air-dried, and dissolved in $50 \mu \mathrm{l}$ of sterile water.

A region of $16 \mathrm{~S}$ from Liberibacter was amplified using PCR with Invitrogen Amplitaq Gold 360 PCR Master Mix (Invitrogen, Carlsbad, CA) and the primers OA2- GCG CTT ATT TTT AAT AGG AGC GGC A and OI2c-GCC TCG CGA CTT CGC AAC CCAT under the following conditions: $4{ }^{\circ} \mathrm{C}$ for $2 \mathrm{~min}$, then 40 cycles of $94^{\circ} \mathrm{C}$ for $30 \mathrm{~s}, 65^{\circ} \mathrm{C}$ for $30 \mathrm{~s}$, and $72{ }^{\circ} \mathrm{C}$ for $60 \mathrm{~s}$, followed by a final incubation at $72{ }^{\circ} \mathrm{C}$ for 5 min (Jagoueix et al. 1996; Crosslin et al. 2011). The presence or absence of the expected 1,168-bp PCR product was observed on a $1.5 \%$ agarose gel stained with ethidium bromide.

Fluorescence in situ Hybridization Fluorescence in situ hybridization was performed using the methods similar to those of Cooper et al. (2013). The samples were fixed in Carnoy's solution for $1 \mathrm{~h}$, briefly rinsed in $100 \%$ ethanol, and washed three times for $20 \mathrm{~min}$ in hybridization buffer consisting of $20 \mathrm{mM}$ Tris- $\mathrm{HCl}$ (pH 8.0), $0.9 \mathrm{M} \mathrm{NaCl}, 0.01 \%$ sodium dodecyl sulphate, and $30 \%$ formamide. Samples were hybridized overnight at $25{ }^{\circ} \mathrm{C}$ with 250 picomoles $/ \mathrm{ml}$ of HPLCpurified oligonucleotide probe labeled with Alexa Fluor 488 on the 5-prime end (Invitrogen, Carlsbad, CA) and dispersed in hybridization buffer. The $16 \mathrm{~S}$ probe sequence was GCC TCG CGA CTT CGC AAC CCA T. No-probe controls (stems from 2 plants in each trial) were hybridized in buffer without the oligonucleotide probe. After hybridization, samples were briefly washed in hybridization buffer, followed by two washes for 20 min each in hybridization buffer, and one 20 min wash in TRIS-buffered saline. The presence of Liberibacter was observed at $200 \times$ using a fluorescence microscope (Zeis Axioskop $40 \mathrm{FL}$ ) with Zeiss filter-set 09 (excitation wavelength $=450-490 \mathrm{~nm}$, beam splitter $=510 \mathrm{~nm}$, and emission wavelength $=515 \mathrm{~nm}$ ).

Statistical Analyses Data were analyzed using logistic regression (PROC LOGISTIC, SAS Institute 2012). A single analysis compared the probability of rhodamine $\mathrm{B}$ migration from 
Fig. 1 Migration of rhodamine B from leaf 0 to leaves -1 and 1 through 5. Proportion of leaves a and the three terminal leaflets of each leaf $\mathbf{b}$ that accumulated rhodamine $\mathrm{B}$ that was introduced in leaf position 0. Error bars represent $95 \%$ confidence intervals and different letters denote significant differences $(\alpha=0.05)$ among leaves $\mathbf{a}$ or among leaflets of each leaf $\mathbf{b}$

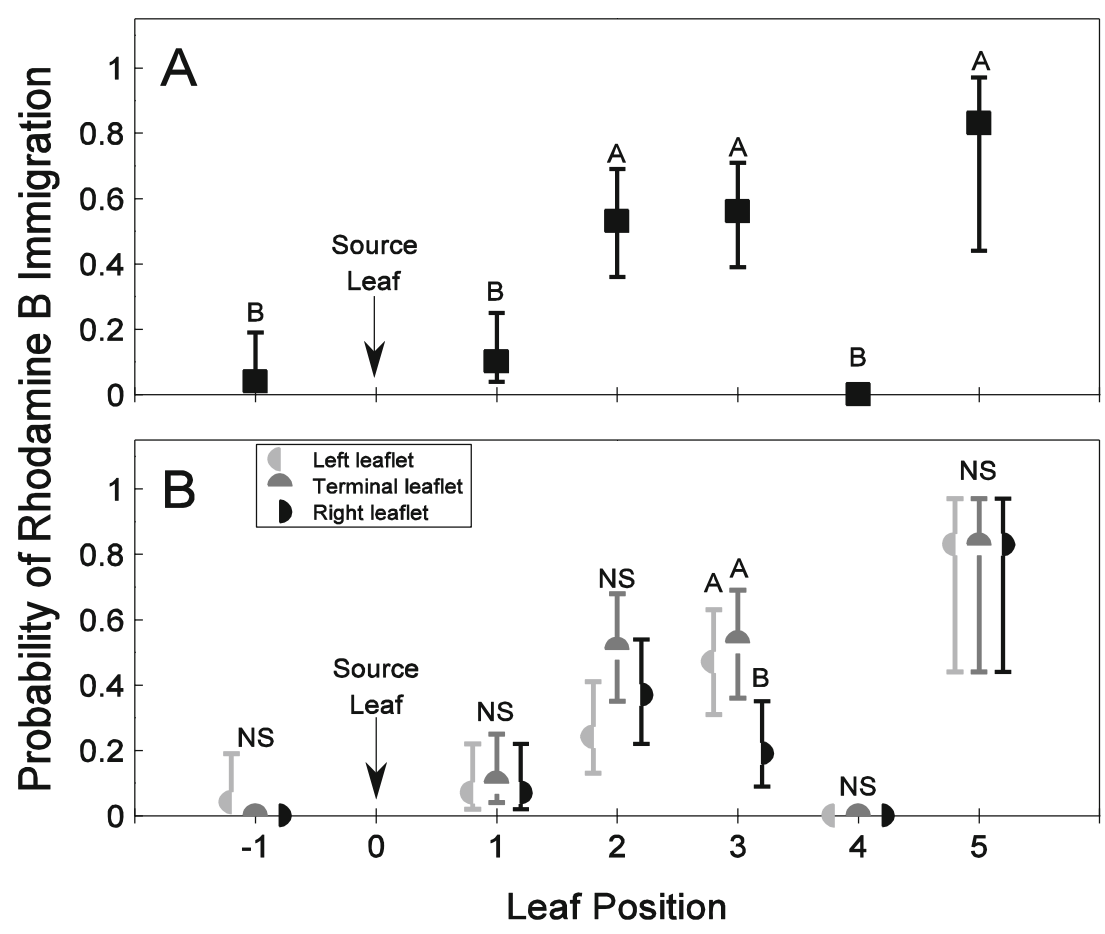

leaf 0 to other leaves, regardless of leaflet position. Separate logistic regression analyses of each leaf compared the probability of dye accumulating in each of the three terminal leaflets (right leaflet, terminal leaflet, and left leaflet with the petiole toward the top). Similar analyses compared the probability of Liberibacter infection among leaves regardless of leaflet position, and in leaflets of each leaf. Based on results of the experiments assessing the migration of rhodamine $\mathrm{B}$, each leaflet was categorized as having either a direct or indirect vascular connection with leaf 0 . Logistic regression was used to compare the probability of Liberibacter infecting leaflets with direct or indirect connectivity with leaf 03 weeks after pathogen-inoculation. Whole leaves were categorized as having indirect (rhodamine did not accumulate in leaves), partial (rhodamine accumulated in part of the leaf), or direct (rhodamine accumulated in the entire leaf) vascular connections with leaf 0 , and the probability of Liberibacter-infection was compared among psyllids confined to these leaves using logistic regression. The FIRTH option of the MODEL statement was included in all analyses to correct for small sample sizes, and significant differences among response variables were compared using Wald $95 \%$ confidence intervals.

\section{Results and Discussion}

Migration of Rhodamine $B$ Logistic regression analysis indicated significant differences in the probability of rhodamine $B$ migrating to leaves $-1,1,2,3,4$, and 5 from the export leaf (leaf 0$)\left(\chi^{2}=32.5\right.$; d.f. $=5, P<0.01$; Fig. 1A). The probability of rhodamine B migrating to leaves 2,3 , and 5 was greater than the probability of rhodamine B migrating to leaves $-1,1$, and 4 (Fig. 1A). Logistic regression analyses also indicated within-leaf variability in the probability of rhodamine B immigration in leaf 3 , but not in other leaves (Table 1). In leaf 3, the probability of the dye migrating to the left and terminal leaflets was greater than the probability of the dye migrating to the right leaflet (Fig. 1B). Although not significant at the $\alpha=$ 0.05 (Table 1), the opposite trend was observed in leaf 2 (Fig. 1B). The dye was observed in the right and terminal

Table 1 Analyses examining the probability of rhodamine B or Liberibacter migrating from leaf 0 to each of the three most terminal leaflets of leaves $-1,1,2,3,4$, and 5 (numbered relative to the export leaf 0 )

\begin{tabular}{lclllll}
\hline & Leaf $-1 \chi^{2}(\mathrm{P})^{\mathrm{a}}$ & Leaf $1 \chi^{2}(\mathrm{P})^{\mathrm{a}}$ & Leaf 2 $\chi^{2}(\mathrm{P})^{\mathrm{a}}$ & Leaf 3 $\chi^{2}(\mathrm{P})^{\mathrm{a}}$ & ${\text { Leaf } 4 \chi^{2}(\mathrm{P})^{\mathrm{a}}}_{\text {Leaf }^{2} \chi^{2}(\mathrm{P})^{\mathrm{a}}}$ \\
\hline Rhodamine B & $0.1(0.98)$ & $0.3(0.88)$ & $5.1(0.08)$ & $8.8(0.01)$ & $<0.1(1.0)$ & $<0.1(1.0)$ \\
Liberibacter Infection & $0.77(0.68)$ & $2.4(0.30)$ & $0.2(0.90)$ & $0.19(0.91)$ & $3.7(0.16)$ & $1.7(0.42)$ \\
\hline
\end{tabular}

${ }^{\text {a }}$ Degrees of freedom $=2$ 
Fig. 2 Vascular connectivity among leaves of potato plants. Rhodamine B tended to accumulate in the right side of leaf 2 , in the left side of leaf 3 , and in all of leaf 5 a. Diagram $\mathbf{b}$ of vascular bundles in a stem, shown as though the cylinder of the stem were unrolled to a flat plane (after Dimond 1966). The shaded area represents presumed direct vascular connections from leaf 0 to half of leaves 2 and 3 , and all of leaf 5
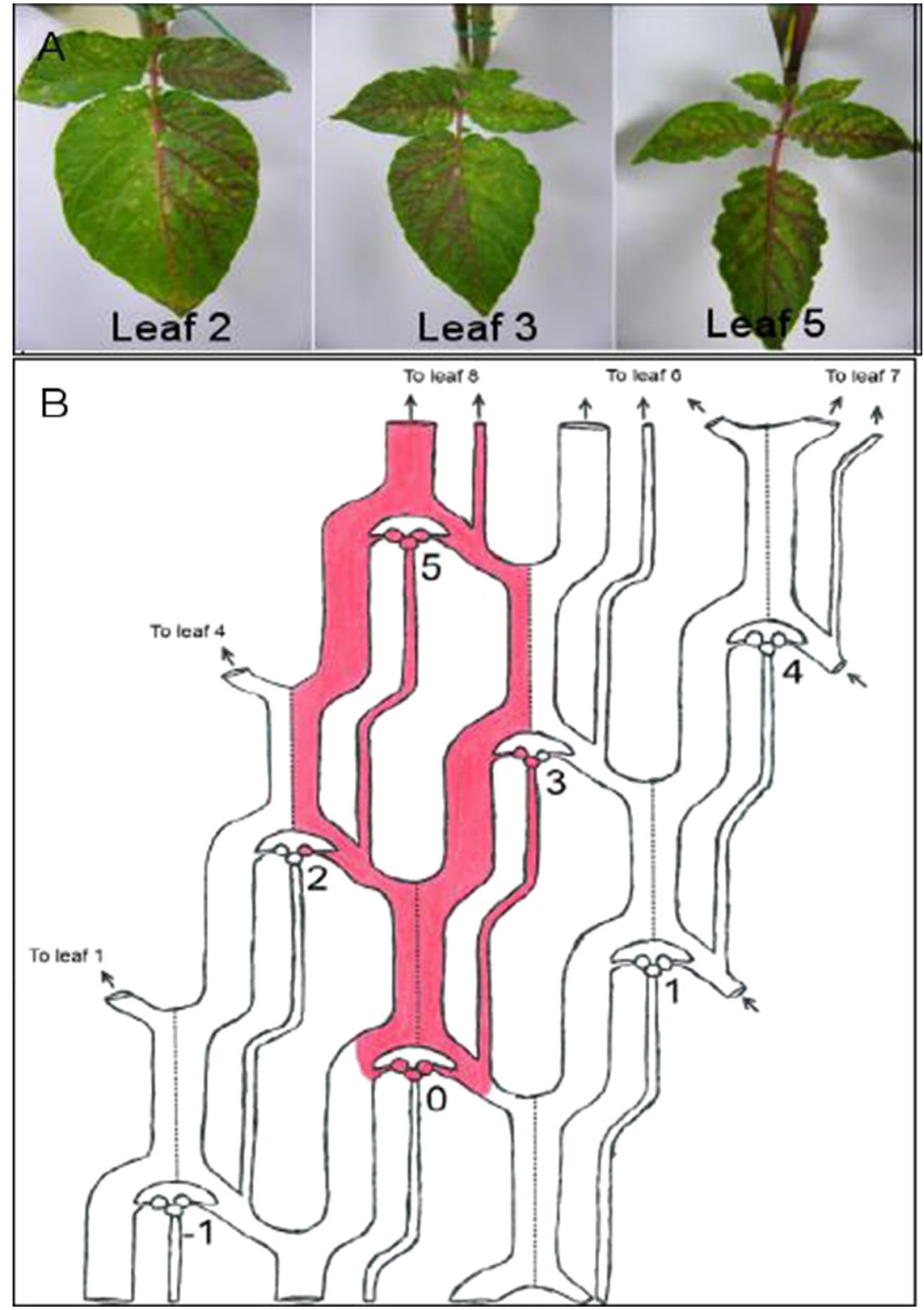

leaflets of leaf 2 more often than in the left leaflet. When the dye was observed in all three leaflets of leaves 2 and 3, the dye tended to be more concentrated in the right leaflet and in the right half of the terminal leaflet in leaf 2 , and in the left leaflet and left half of the terminal leaflet in leaf 3 (Fig. 2A). Although this trend in which the dye accumulated in the right half of leaf 2 and in the left half of leaf 3 was observed in most plants, the opposite was observed 6 out of 24 plants where the dye accumulated in the left half of leaf 2 and in the right half of leaf 3 . The dye always accumulated uniformly in each of the three leaflets of leaf 5. Our results suggest that patterns in vascular connectivity of potato are similar to those reported in tomato (Dimond 1966; Orians et al. 2000): the right half of leaf 2 , left half of leaf 3 , and all of leaf 5 share direct vascular connections with the export leaf, whereas leaves $-1,1$, and 4 have minimal vascular connections with the export leaf (Fig. 2B).

Migration of Liberibacter The two bottom-most leaves (leaves -1 and 0 ) typically excised from plants that were infested with Liberibacter-infected psyllids before the leaves were collected 3 weeks after inoculation. Therefore, leaf -1 was excluded from the analyses. Plants from which Liberibacter was not detected in any leaves were also excluded from the analyses ( 2 plants from trial 1 and 4 plants from trial 2). Logistic regression did not indicate that the probability of Liberibacter infection in leaves 1 through 5 differed $\left(\chi^{2}=\right.$ 3.7; d.f. $=5, P=0.60$ ) (Fig. 3A), nor did analyses indicate significant within-leaf variability in Liberibacter infection in 


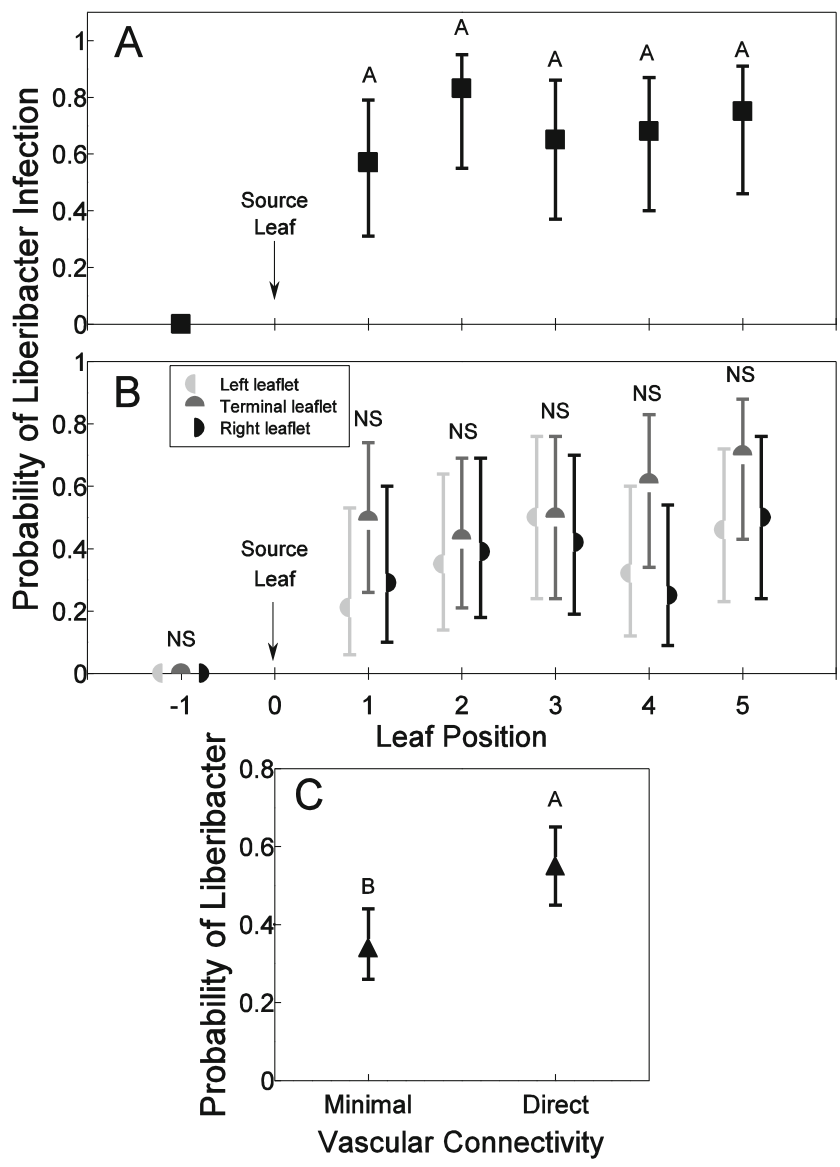

Fig. 3 Liberibacter-infection in leaves -1 and 1 through 5 three weeks after confining Liberibacter-infected psyllids to leaf 0 . Proportion of leaves $\mathbf{a}$, the three terminal leaflets of each leaf $\mathbf{b}$, or leaflets with minimal or direct vascular connections with leaf $0 \mathbf{c}$ that were infected with Liberibacter. Error bars represent $95 \%$ confidence intervals and different letters denote significant differences among categories of vascular connectivity $(\alpha=0.05)$

leaves 1 through 5 (Table 1; Fig. 3B). Observed patterns in Liberibacter infection, although non-significant, were generally consistent with those observed for migration of rhodamine B. Liberibacter rarely infected leaf -1 , tended to be located on the right side of leaf 2 , on left side of leaf 3 , and uniformly distributed in leaf 5 (Figs. 4A and B). These trends that are less than statistically significant at $5 \%$ were observed in both independent trials, and point to variation that needs to be tested in future, more focused studies. Although analyses did not provide evidence of significant within-plant variability in Liberibacter infection, the probability of Liberibacter infection was significantly greater in leaflets with direct vascular connections (right and terminal leaflets of leaf 2, left and terminal leaflets of leaf 3 , and all three leaflets of leaf 5) than in leaflets with minimal vascular connections $(\chi 2=8.8$; d.f. $=$ $1 ; P<0.01$; Fig. 3C).

Methods used in these initial experiments measured the establishment of Liberibacter in leaves 3 weeks after the initial inoculation, which might not accurately represent actual migration of the pathogen from the export leaf if other factors influence the establishment of Liberibacter in the import leaves. Our experiment in which we confined Liberibacterinfected psyllids to leaf 0 and non-infected psyllids to each of leaves 1 through 5 , and then assessed Liberibacter-infection in psyllids after 1 week was designed to more directly measure migration rather than establishment of Liberibacter. This experimental design assumed that psyllids can acquire the pathogen as it immigrates into a leaf, regardless of factors that may reduce the probability of the pathogen becoming established in certain leaves. Logistic regression indicated significant differences in the probability of psyllids confined to leaves 1 through 5 acquiring Liberibacter from the infected psyllids on leaf 0 (Fig. $4 ; \chi^{2}=18.9$; d.f. $=5 ; P=0.002$ ). Psyllids confined to leaf 5 had a significantly greater probability of acquiring Liberibacter than did psyllids confined to leaves 1-3 (Fig. 4A). In a separate analysis, psyllids confined to leaves with direct vascular connectivity to leaf 0 (leaf 5) had a significantly greater probability of acquiring Liberibacter than did psyllids confined to leaves with only partial connectivity (leaves 2 and 3) or minimal connectivity (leaves 1 and 4) with leaf 0 (Fig. 4B; $\chi^{2}=12.1$; d.f. $=2 ; P=0.002$ ).

Fluorescence in situ Hybridization Rhodamine B was typically observed in the inner phloem above the export leaf (Fig. 5A) and in the outer phloem below the export leaf (Fig. 5B) corresponding with upward movement in the inner phloem and downward movement in the outer phloem. If the movement of Liberibacter is restricted by vascular architecture, we would expect Liberibacter to follow the same trend as rhodamine B: present in the inner and outer phloem above and below the export leaf, respectively.

When observed under the fluorescent microscope, the vascular tissues autofluoresced yellow regardless of treatment (Fig. 5C, D). However, the yellow autofluorescence was more intense in plants infested with Liberibacter-infested psyllids, and followed a pattern similar to that observed for rhodamine $\mathrm{B}$ (Fig. $5 \mathrm{E}$ and $5 \mathrm{~F}$ ). The induced autofluorescence was also observed in samples hybridized without the Liberibacter probe. Presumably, the induced autofluorescence corresponded with induction of phenolics such as lignin following Liberibacter infection (Navarre et al. 2009; Miles et al. 2010). The intense yellow autofluorescence impeded the observation of green fluorescence associated with the Alexa 488 probe designed to bind with Liberibacter. However, slight green fluorescence was typically observed in the inner phloem above leaf 0 and in the outer phloem below leaf 0 . The induced yellow autofluorescence was not as intense in samples processed 1 week after Liberibacter inoculation compared with samples processed 3 weeks after inoculation, thus allowing better observation of green fluorescence indicating the presence of Liberibacter. Observations of samples 
Fig. 4 Acquisition of Liberibacter by psyllids after 1 week. Probability of noninfected psyllids confined to leaves 1 through 5 acquiring Liberibacter after 1 week from infected psyllids confined to leaf 0 a. Probability of psyllids confined to leaves with minimal, partial, or direct vascular connections with leaf 0 acquiring Liberibacter b. Error bars represent $95 \%$ confidence intervals and different letters denote significant differences among leaves or categories of vascular connectivity $(\alpha=0.05)$

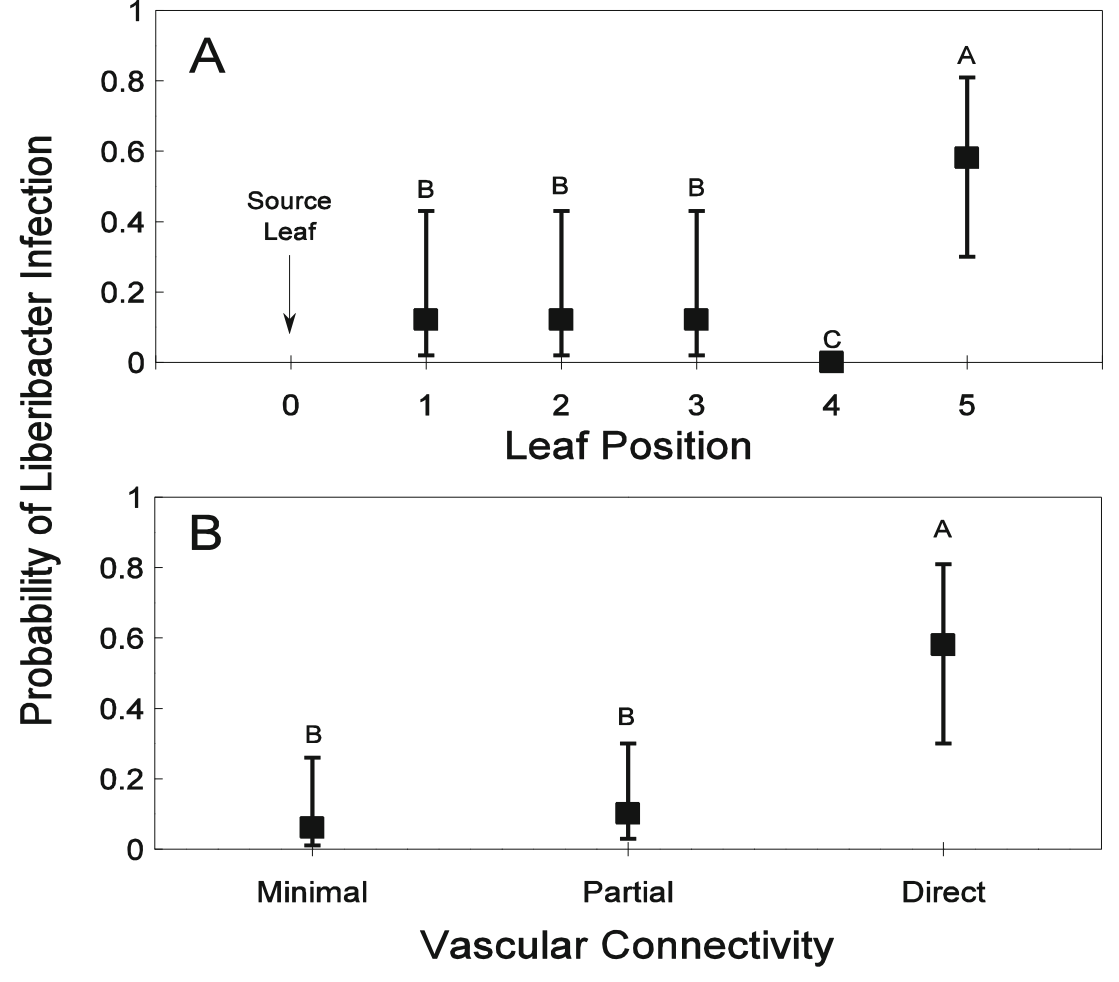

processed 1 week after Liberibacter inoculation confirmed the presence of Liberibacter primarily in the inner phloem above the export leaf (Fig. 5F) and in the outer phloem below the export leaf (Fig. 5G).

Conclusions Results of this study suggest that the transport of ' $C a$. Liberibacter solanacearum' from the inoculation leaf to other leaves is at least partially limited by vascular connectivity. The role of vascular architecture in contributing to withinplant variability of Liberibacter infection is supported by 1) significantly more leaflets with direct vascular connectivity with the inoculation leaf compared with those with minimal connectivity becoming infected with Liberibacter 3 weeks after the initial inoculation, 2) significantly greater acquisition of Liberibacter by psyllids confined to leaves with direct vascular connectivity with the inoculation leaf compared with psyllids confined to leaves with minimal or partial connectivity, and 3) the presence of Liberibacter in the inner phloem above the inoculation leaf and in the outer phloem below the inoculation leaf. This is the first study to investigate the influence of vascular architecture on within-plant distribution of a Liberibacter species. Results of our study contrast with those from studies which investigated the movement of phytoplasmas, another taxonomic group of insect-vectored bacterial plant pathogens whose translocation does not appear to be influenced by vascular architecture (Kuske and Kirkpatrick 1992; Constable et al. 2003; Christensen et al. 2004).
Although results of our study suggest that vascular architecture influences the initial distribution of ' $\mathrm{Ca}$. Liberibacter solanacearum' in potato plants, other factors likely contribute to the within-plant variability of Liberibacter infection. Liberibacter infection leads to the induction of salicylic aciddependent defenses (systemic acquired resistance) in potato (Navarre et al. 2009). Previous reports indicated that vascular architecture generates within-plant variation in induction of acquired defenses, and that the strength of acquired defenses is greater in leaves with direct vascular connectivity with the attacked leaf compared with leaves with minimal connectivity (Shulaev et al. 1995; Orians et al. 2000). It seems possible that acquired defenses activated by initial pathogen attack (in leaf 0 ) could reduce the probability of Liberibacter infection in leaves with direct vascular connections with the inoculation leaf regardless of the increased immigration of the pathogen to these same leaves. In this case, vascular architecture could contribute to the within-plant spatial variation of Liberibacter infection by influencing the initial distribution of the pathogen (migration of the pathogen) as well as variability in acquired defenses (establishment of the pathogen). Another factor that may contribute to the within-plant variability in Liberibacter infection is disruption or manipulation of phloem transport in Liberibacter-infected plants (Koh et al. 2011; Brodersen et al. 2014). Finally, genes putatively involved in the assembly of flagella and pili have been identified from Liberibacter, so it is possible that this pathogen is motile under certain conditions (Lin et al. 2011). 
Fig. 5 Presence of Liberibacter in potato stems. Rhodamine B in the inner phloem above the source leaf $\mathbf{a}$ and in the outer phloem below source leaf $\mathbf{b}$.

Autofluorescence of vascular tissues in stems above $\mathbf{c}$ and below $\mathbf{d}$ a leaf infested with noninfected psyllids 1 weeks earlier. Autofluorescence of vascular tissues in the inner phloem of a stem above the source leaf $\mathbf{e}$ and in the inner (F, black arrow) and outer $(\mathrm{F}$, white arrow) phloem of a stem below the source leaf 3 weeks after inoculation with Liberibacter-infected psyllids. Green fluorescence indicating Liberibacter infection in the inner phloem of a stem above the source leaf $\mathbf{g}$ and in the outer phloem below the source leaf $\mathbf{f}$ 1 week after inoculation with Liberibacter
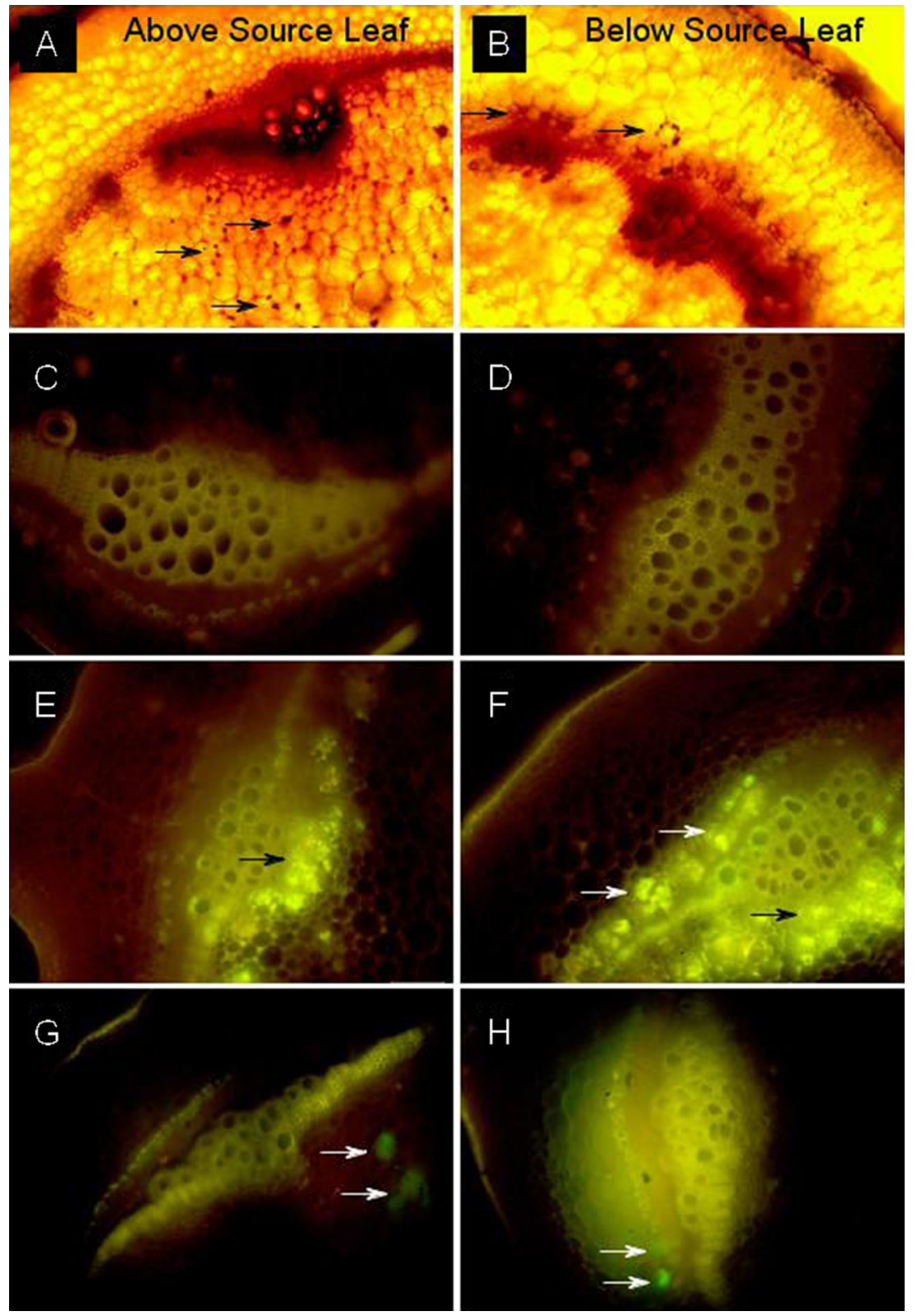

Our findings that vascular architecture influences the within-plant variability in Liberibacter infection of potato could improve the early diagnosis of plants exposed to Liberibacter before the onset of disease symptoms, or in plants that are tolerant to Liberibacter-injury. For example, assuming that the site of inoculation is unknown, sampling several leaves with indirect vascular connections (for example leaves 0,1 , and 4) would increase the probability of detecting Liberibacter in an asymptomatic plant because such a procedure would sample more potential pathways for inoculated pathogens than sampling single leaves or leaves from arbitrary locations on a plant. The documentation of the influence of vascular architecture on Liberibacter movement in plants should also be useful in the control of biological variability in studies investigating Liberibacter - plant interactions and plant defenses against this pathogen.

Acknowledgments Heather Headrick and Pauline Anderson provided technical assistance. Piedad Alcala was supported by NSF-REU Award \# 1156603 to Heritage University (PI Nina Barcenas). Mention of trade names or commercial products in this article is solely for the purpose of providing specific information and does not imply recommendation or endorsement by the United States Department of Agriculture. USDA is an equal opportunity provider and employer.

Open Access This article is distributed under the terms of the Creative Commons Attribution License which permits any use, distribution, and reproduction in any medium, provided the original author(s) and the source are credited. 


\section{References}

Andrianifahanana, M., K. Lovins, R. Dute, E. Sikora, and J.F. Murphy. 1997. Pathway for phloem-dependent movement of pepper mottle potyvirus in the stem of Capsicum annuum. Phytopathology 87: 892-898.

Brodersen, C., C. Narciso, M. Reed, and E. Etxeberria. 2014. Phloem production in Huanglongbing-affected citrus trees. Hortscience 49: $59-64$.

Christensen, N.M., M. Nicolaisen, M. Hansen, and A. Schulz. 2004. Distribution of phytoplasmas in infected plants as revealed by realtime PCR and bioimaging. Mol Plant-Microbe Interact 17: 11751184.

Constable, F.E., K.S. Gibb, and R.H. Symons. 2003. Seasonal distribution of phytoplasmas in Australian grapevines. Journal of Plant Pathology 52: 267-276.

Cooper, W.R., V.G. Sengoda, and J.E. Munyaneza. 2013. Localization of 'Candidatus Liberibacter solanacearum' (Rhizobiales: Rhizobiaceae) in Bactericera cockerelli (Hemiptera: Triozidae). Ann Entomol Soc Am 107: 204-210.

Crosslin, J.M., H. Lin, and J.E. Munyaneza. 2011. Detection of 'Candidatus Liberibacter solanacearum' in the potato psyllid, Bactericera cockerelli (Sulc), by conventional and real-time PCR. Southwestern Entomologist 36: 125-135.

Dimond, A.E. 1966. Pressure and flow relations in vascular bundles of the tomato plant. Journal of Plant Physiology 41: 119-131.

Gosalvez-Bernal, B., A. Genoves, J.A. Navarro, V. Pallas, and A. Sanchez-Pina. 2008. Distribution and pathway for phloemdependent movement of Melon necrotic spot virus in melon plants. Molecular Plant Pathology 9: 447-461.

Jagoueix, S., J. M. Bove, and M. Garnier. 1996. PCR detection of the two 'Candidatus' Liberobacter species associated with greening disease of citrus. Molecular and Cellular Probes 10: 43-50

Koh, E., L. Zhou, D.S. Williams, J. Park, N. Ding, Y. Duan, and B. Kang. 2011. Callose deposition in the phloem plasmodesmata and inhibition of phloem transport in citrus leaves infected with "Candidatus Liberibacter asiaticus.”. Protoplasma 249: 687-697.

Kuske, C.R., and B.C. Kirkpatrick. 1992. Distribution and multiplication of western aster yellows mycoplasmalike organisms in Catharanthus roseus as determined by DNA hybridization analysis. Phytopathology 82: 457-462.

Leisner, S. M., R. Turgeon, and S. H. Howell. 1992. Long distance movement of cauliflower mosaic virus in infected turnip plants. Molecular Plant-Microbe Interactions 5: 41-47

Levy, J., A. Ravindran, D. Gross, C. Tamborindeguy, and E. Pierson. 2011. Translocation of 'Candidatus Liberibacter solanacearum', the zebra chip pathogen, in potato and tomato. Phytopathology 101: 1285-1291.

Lin, H., B. Lou, J.M. Glynn, H. Doddapaneni, E.L. Civerolo, C. Chen, Y. Duan, L. Zhou, and C.M. Vahling. 2011. The complete genome sequence of 'Candidatus Liberibacter solanacearum', the bacterium associated with potato zebra chip disease. PLoS One 6: e19135. doi: 10.1371/journal.pone.0019135.

McCauley, M.M., and R.F. Evert. 1988. Morphology and vascularture of the leaf of potato (Solanum tuberosum). American Journal of Botany 75: 531-540.

Miles, G.P., M.A. Samuel, J. Chen, E.L. Civerolo, and J.E. Munyaneza. 2010. Evidence that cell death is associated with zebra chip disease of potato tubers. American Journal of Potato Research 87: 337-349.

Munyaneza, J.E. 2012. Zebra chip disease of potato: Biology, epidemiology, and management. American Journal of Potato Research 89: 329-350.

Navarre, D.A., R. Shakya, J. Holden, and J.M. Crosslin. 2009. LC-MS analysis of phenolic compounds in tubers showing zebra chip symptoms. American Journal of Potato Research 86: 88-95.

Orians, C.M. 2005. Herbivores, vascular pathways, and systemic induction: Facts and artifacts. Journal Chemistry Ecology 31: 2231-2242.

Orians, C.M., J. Pomerleua, and R. Ricco. 2000. Vascular architecture generate fine scale variation in systemic induction of proteinase inhibitors in tomato. Journal Chemistry Ecology 26: $471-485$.

SAS Institute. 2012. SAS release 9.3 ed. SAS Institute, Cary, NC.

Sengoda, V.G., J.L. Buchman, D.C. Henne, H.R. Pappu, and J.E. Munyaneza. 2013. 'Candidatus Liberibacter solanacearum' titer over time in the Bactericera cockerelli (Hemiptera: Triozidae) after acquisition from infected potato and tomato plants. Journal Economics Entomol 106: 1964-1972.

Shulaev, V., J. Leon, and I. Raskin. 1995. Is salicylic acid a translocated signal of systemic acquired resistance in tobacco? Plant Cells 7 : 1691-1701.

Swisher, K.D., V.G. Sengoda, J. Dixon, E. Echegaray, A.F. Murphy, S.I. Rondon, J.E. Munyaneza, and J.M. Crosslin. 2013a. Haplotypes of the potato psyllid, Bactericera cockerelli, on the wild host plant, Solanum dulcamara, in the Pacific Northwestern United States. American Journal of Potato Research 90: 570-577.

Swisher, K.D., J.E. Munyaneza, and J.M. Crosslin. 2013b. Temporal and spatial analysis of potato psyllid haplotypes in the United States. Environment Entomol 42: 381-393.

Zhang, Y.P., J.K. Uyemoto, and B.C. Kirkpatrick. 1998. A small-scale procedure for extracting nucleic acid from woody plants infected with various phytopathogens for PCR assay. Journal Virology Methods 71: 45-50. 